\title{
School Dropouts - Pedagogy as an Instrument for Prevention
}

\author{
Dr. Florinda Tarusha \\ Faculty of Educational Sciences \\ "Aleksander Xhuvani" University, Elbasan, Albania \\ Email: ftarusha@yahoo.com
}

\section{Doi:10.5901/jesr.2014.v4n2p460}

\begin{abstract}
Nowadays, school dropout has become a phenomenon that affects education, school and civil society alike. A large number of children in Albania do not attend school; they are not registered in them and do not have a permanent work either. This category of children does not have opportunities for an assured future and professional integration since they do not fit to the today's market requirements. This study offers some recommendations to those organizations and institutions that are focused in the education and social development field, in order to design intervention policies and become more focused in the process of compiling and reviewing projects that fit actual necessities.
\end{abstract}

Keywords: School dropout, prediction, intervention, prevention, rehabilitation

The phenomenon of not attending school by children and youth is as old as the school itself. But what are the reasons for such an attitude? Do they really dislike going to school? Do we have to look for causes in the organization of subjects or in the school institutions itself, or do pupils transmit their family problems at school? How can we work out such situations? Do we have to reorganize school as an institution? Is the social work functioning in the right way at school?

Nowadays, living conditions of youngsters have changed too fast. In order to explain correctly the youth problems at school, it is important to explain their position in the society first. Conditioned by the slow development of a society that is oriented in capital and money towards a modern society interested in knowledge and education, the social structure is changing as well. Today needs are for flexible people with knowledge in different fields, willing to learn, to develop critical abilities, working in groups, social, cultural and creative competences.

\section{Strategy and preventions}

As analyzed above, the conditions and consequences of the phenomenon of dropping out from school, the early problem on reaching considerable grades since the very first year of school, they might experience abnormal development in the future and influence negatively their entire school and professional carrier.

It is important to be shown a very effective manner toward pupils disconformities and act in the right moment by taking prevention to the phenomenon of dropping out of school. A large number of pupils dropout because they do not receive the right support in the right moment and they do not have any encouragement from it. A positive commitment of teacher to their pupils, a positive learning environment, feasible organization of lesson hours and e very transparent way of assessment, is a very important element in their school commitment.

Failure and dropping out of school can be very often a lack of encouragement toward them to reach good results, to expand their personality in the environment. Strategies that should be designed and the preventions that should be undertaken to avoid drop-out must be long-term, otherwise they will not reach the expected results. They lose their effectiveness if they are not applied during the whole period of school. The key components for the early identification of pupils that might drop out of school are:

- Prediction: the process for the early prediction of pupils who have a tendency for dropping out of school

- Intervention: programs and initiatives that help pupils in danger

- Prevention: includes the ways for the organization of school programs which might minimize the possibilities for pupils to become a contingent for dropping-out

- Rehabilitation: includes the possibilities for the training of pupils in danger in the cases when interventions and preventions are not sufficient

Prediction includes the ways of identification of pupils that have a tendency for dropping out school. Most of pupils that 
drop school out are the result of bad experiences. They stress out the fact that this is the cause of elements related to school, family reasons or personal ones. This stands for every demographic group. To identify pupils in danger we should take into consideration those ones with low grades in the principal subjects, those with a low attendance and those who are not active at school.

Schafer ${ }^{1}$ predicates that teachers can identify this in the early period of this phenomenon. Parents, teachers and social workers can prevent the early tendencies for dropping out. School should identify the possibilities that pupils have in order to be integrated in the social group. On the other side, if they cannot, they should develop some strategies of adaptation for those pupils. Pupils in danger, have a very long list of characteristics:

- Demographic background (poor pupils, learning and emotional disabilities, kinesthetic pupils, older pupils in a classroom. This is the category that is mostly affected).

- Family factors (pupils with one parent, pupils with parents that have low level education, pupils with parents that do not support them or have brothers and sisters that have not finished school)

- Grown up responsibilities (teenagers that take the role of a grown up, being a parent in an early age, marriage or working during school time).

- Educational experiences (those who drop out from school had low grades, have been weak in math and in language subjects. These pupils have very little possibilities to be graduated. They also have a low commitment level at school, they have high level of absences, bad behaviors in class, low frequentation in the extracurricular activities and bad relationship with teachers and their friends. All these are the elements that show that they will not be graduated.

Several studies ${ }^{2}$ show that it is possible to predict the drop out of school by being very careful: this can happen if there is a close look to a group of pupils that have started the school at the same time and at the same age. By being focused on this, analysts can find out examples which prevent the drop out and they can identify factors in danger which are the best predictors of this problem.

Intervention. After the identification of pupils in danger it is important to take some provisions. Continuous attention by the teacher can reduce the level of drop out even for those pupils that have more tendency to do it. In this case, the need of social workers seems to be very important to monitor the continuity of every pupil and their performance, where the intervention can occur from the first moment in order to help them and their families to overcome the difficulties and succeed in solving that problem.

Related to the intervention provisions, a very important role is that of the cooperation of school with the family. This cooperation consists on the fact that family should inform school in the cases when they will not attend it. In the time that school is aware of the pupils' absences, they should inform their parents in the right moment to intervene.

Intervention provisions should include school, classrooms and familiar environment.

- school environment, for example: development and draw of a concept on the school institution in offering consoling sessions

- class environment, for example, draw of common codes, project work

- familiar environment, for example family visits

- $\quad$ pupils environment, for example encouragement of social connections and competences

From studies and research in this field, it results that some schools or educational centres have implemeted some intervention programs, which have shown very promising results. What is important, is that in order to adapt an intervention program, school boards should be informed if the program has been valuated from the outsiders (if it has been implemented from others as well) and if these evaluations have used solid research methods. Intervention must be target.

Prevention: includes ways in which school must minimize danger factors

- A good preparation of pupils in low classes helps them have good grades in higher ones

- Classroom size and curricular quality at school are very important. Pupils that attend college in smaller classrooms, that have good interpersonal relationship with the older ones, that have teachers that support them and have a very useful curriculum, do not have e high level of tendency to drop out the school

- Some school models in high schools can help pupils to continue their studies.

\footnotetext{
1 Schäfer, Hainer: Präventive Jugendsozialarbeit mit schwierigen Schülern. Werkstattbericht. München 1998 fq.51. 2

2 Early Intervention Strategies for Children and Young people 8 to 14 Years. NSW Department of Community Services, July 2008
} 


\section{What should be done in the moments when interventions and preventions are sufficient?}

Effective intervention and prevention strategies can reduce in a considerable manner the number of pupils that have a tendency to drop out of school. Re-establishment programs can offer a second opportunity for pupils that drop out despite school's effort. Most of them who drop out do regret and later on they want a diploma. The first step for intervention in the re-establishment programs is by taking into consideration the analyses of the data in order to define the number and characteristics of those who will profit from them. None of the group strategy has been proved to be $100 \%$ effective. Not all of those who drop the school out have early visible signs. None of those pupils that have been part of the intervention reached a good result.

Based on the contemporary studies on the drop-out of school, there can be stressed five basic principles, which local educational directories should take into consideration before they invest in the prohibitive programs, intervention and prevention.

First: educational experiences (school attendance) are the best showing elements for school drop out that are race, poverty, age, sex and personal conditions. Although teachers believe that the drop out of school is caused by family and personal conditions that have nothing to do with school, most of them do manifest some premonition signs. This conclusion is supported even by the study results.

Second: for most of the pupils that drop out the school, this is something unexpected. In reality, most of them follow the models of school continuity by showing signs of difficulty in the learning process and disengagement before the start of high school and sometimes even before it. This means that schools and their directories can identify the major part of drops out much earlier so that it can be intervened.

Third: when passing from one level to another, one can make a critical way toward graduation and most of the eventual dropping out firstly show their signs during the first year when they start the elementary or high school. Pupils in this period find out that course papers are very difficult and teachers are less supportive that those in the previous level; relations with friends are more complicated; pupils are more autonomous and less supervised. Problems start very early and the trustful ones are: low level of grades and frequentation can be observed since at the beginning of the school year.

Fourth: frequentation and learning achievements, both this issues are very important in showing which of the pupils has a tendency for not being graduated- this issue has been very confused. The truth seems to be the learning performance and the frequency at school have the same importance and most of the time they are connected with one another. This is also proved by Fini ${ }^{3}$ who argued

that the disengagement manifested in absences, bad behaviors and bad involvement makes them be evaluated with low grades. Simply, pupils that have not taken an active part at school, that do not show up at school are the ones that most predisposed to drop it out. In the other part, failure of subjects caused by the insufficient abilities or lack of effort and this can cause them the feeling that they are abandoned by school. This leads to the biggest drawback from school.

Fifth: it is dangerous to accept that directories can hypothesize in precise way that which prevention for an educational performance and educational commitment can be the best prediction.

Making a research on the early dropping out factors is very complicated and expensive. Directories can just study the data of pupils registered during years, continuity, performance by collecting information for those ones that have finished school because this is a process that demands time. Except the above prevention, a very important role in diminishing the phenomenon of dropping out of school is social work at school. The main objective of social work at school is social and professional integration. It stresses out the enforcement of the integrated function of school. "Social work at school is indispensable in the cases when pedagogical and social competences are indispensable in the moments when psychosocial conditions and spiritual problems make it difficult to learn, in the moments when social discrimination threatens the individuals, in the moments when social competences should be supported 4 .

\section{Social work at school}

Youth see the graduation not only as a condition for a profession but also as an opportunity for knowledge and social integration. School concept as an "experience profit space" is a pedagogical concept that offers a different prospective in changing today's school. This concept offers a new organization of school and stressed its orientation towards youth' life

\footnotetext{
${ }^{3}$ Finn, J. D. (1993). School engagement and students at risk. Washington, DC:U.S. Department of Education. Fq. 33

${ }^{4}$ Engel, T. (2006) Schulverweigerung: Schulsozialarbeit als pädagogische Intervention. Fq 26 
by becoming a very important pedagogical institution which helps them organize their life in a productive and useful way and also creating and developing the necessary competences in the development of their identity. "At school", "near school", "with school" and outside it, there should be accumulated knowledge, experiences, evaluation and interpretation ${ }^{5}$. School should not be considered only as a social institution for training and development of abilities and expressiveness, which are very important for youngsters' future, but it should contribute in their personal development, by offering them support in facing the social world and support life' demands in accomplishing development and educational duties. Only in this way school is not going to be considered as a strange institution, whose function and duties are accepted and applied by youth in a distanced and obliged discipline. This is the reason why we recommend as an important prevention the job offers and social help in the school institution. Since the beginning of the new century it has been worked, thought and written a lot about job's topics and social help at school. Most of these publications are referred to specific efforts and experiences in this field. We see social work at school as an orientation and structural opportunity for youth which connect them with work principles and the different formats of counseling. The objective is to find out a way of acting between defined norms and rules of youth for an appropriate behavior. Social work at school should not have to do with organization problems at school and with the pedagogical deficits, but it should fulfill the helping duties of youth. Things such as offering help in accomplishing their home work, talks with parents etc. This should be offered to those pupils who do not have a school support. The main task of social work is to familiarize youth with real life situations in a professional manner, situations which are difficult to be faced by uneducated youth. Social work should offer them ways of organizing their free time through specific social work' methods to those ones that have a tendency in problematic attitudes because of the negative experiences they have experienced before. It is important the cooperation between school and the help given to youth. Social work' institutions should be aware of the capacities, competences and the school conditions in enforcing their function in helping youth. School and social work belong to two different fields of institution and function. They should go on with the cooperation to find a solution in the phenomenon of dropping school out. Below, we propose some models in organizing work and social help at school. It is not easy to define the activity of social work institutions. In relation to school, there are different ways of organizing and financing the social work at school. Based on the world experience and in the contemporary literature, we are going to present different types of organization which expound different concepts in the cooperation of school and social work. In a graphic, the models are presented in this way:

\section{Integration model}

\section{School}

Social work at school

\begin{tabular}{|l|cl|}
\hline Main Complitive & - & School (professional control over the social work) \\
\hline Characteristics & - & Social work duties related to school needs. \\
& - & social organization for pupils and youth in their free time \\
& - & social work, strongly connected in an administrative way with school \\
& - & social work should guarantee the proper organization of work at school \\
\hline Priorities & - & social work became part of the school \\
& - & offering a good cooperation with the teaching staff. \\
\hline Deficiencies & - & limitation of autonomy of social work \\
& - & most of the time its function is only observation \\
& - & it is assigned only in the organization of free time \\
& - & social work became a second hand plan \\
\hline
\end{tabular}

\footnotetext{
${ }^{5}$ Engel, T. (2006) Schulverweigerung: Schulsozialarbeit als pädagogische Intervention. Fq 27
} 


\section{Distance Model}

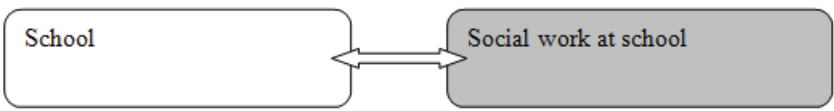

\begin{tabular}{|l|cl|}
\hline Main Complitive & - & School or social work \\
\hline Characteristics: & - & counseling opportunities, attention to youth \\
& - & social work is not directly connected with school \\
& - & task are clearly separated but they can be mixed sometimes \\
& - & free contact between teaching staff and social workers \\
\hline Priorities: & - & high level of autonomy for the social work institutions \\
\hline Priorities: & - & cooperation between teachers and social workers is hardly reached \\
& - & there are little opportunities to influence in the socialization process within the school institution. \\
\hline
\end{tabular}

\section{Cooperation Model}

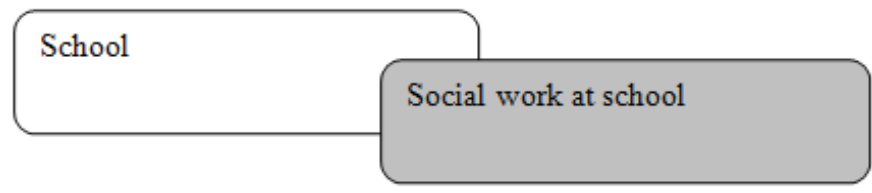

\begin{tabular}{|l|l|}
\hline Main Complitive & - school, social work or other institutions \\
\hline Characteristics: & - Intensive cooperation between school and social work according to a predefined structure \\
& - clearly divided tasks with predefined steps
\end{tabular}

In order to have a good functioning cooperation between school and social work institutions, there should be taken into consideration some factors and conditions that influence in this cooperation.

\section{Youth projects and programs}

There are a considerable number of pupils that percept school as a negative space and experience where they do not find what they are looking for. During classes, there is an insufficient time for each of them especially when one of them has a tendency for deviation.

In these cases, school offers little opportunities to react in an effective way. Learning in our days is still in the traditional manner, frontal learning. There is an absence of concrete situations which makes them passive. In order to avoid drop out tendencies in an effective way, it is necessary to diminish the traditional format of learning so that the learning process can be orientated by projects and practices. Most of the educational experts think that intercession of knowledge should not be done in an isolated way. At the same time they stress the fact that school cannot be isolated only as a place of teaching processes organization, but first of all it is a bridge toward the outer world. For the connection of school life with that of the outer one, there should be build effective interaction structures, there should be a development of communication processes and finding the right partners to cooperate. Framing the concept of helping pupils that drop school out, it should stop the school failure, by offering different projects which take into consideration youngsters both with their complexity. The aim of this concept should raise the number of possibilities for those youngsters that are behind with the integration in their social and professional aspect. School's job is to present the young people to the social reality and its opportunities. As a space where the most important experiences of life are gained, schools should offer different projects of acting in a spontaneous and flexible manner. In order to accomplish 
these projects, school has to offer the necessary and appropriate space where it can be experimented, constructed, organized and planned. All other institutions connected with school can help and support the execution of programs by school. The aim is in offering youth counseling and impulses in organizing their future. These projects help them confront the social life challenges. Especially those pupils who have problems with their grades, can have a very significant help from these projects by offering them an important experience that gives the possibility to be graduated. One of the possible solutions is the counseling of youngsters in education and professions.

\section{References}

Engel, T. (2006): Schulverweigerung Schulsozialarbeit als pädagogische Intervention. VDM Verlag Dr. Müller. Berlin.

Finn, J. D. (1993). School engagement and students at risk. Washington, DC:U.S. Department of Education.

Schäfer, Hainer (1998): Präventive Jugendsozialarbeit mit schwierigen Schülern. Werkstattbericht.München.

Tully, L. (2008): Early intervention strategies for children and young people 8 to 14 years: Literature review. Centre for Parenting and Research, Service System Development, NSW Department of Community Services 